\title{
Load-Bearing Capacity of Traditional Dovetail Carpentry Joints with and Without Dowels: Comparison of Experimental and Analytical Results
}

\author{
Karel Šobra, Coralie Avez, Yasemin D. Aktaş, Richard de Rijk, \\ Isabela Burawska and Jorge M. Branco
}

\begin{abstract}
Post-disaster field studies widely suggest that historical timber structures are seismically resistant, and a growing number of experimental studies support this observation. The joints between structural members, which are the major energy dissipation mechanism within the structure, play a crucial role in the overall robustness and the way that a structure handles the seismic demand. Joints mostly fail when the timber members are still in the elastic range, therefore a thorough understanding of their behaviour under various loading schemes is of utmost importance to gain deeper insight about the overall structural performance of timber structures. This paper summarizes the findings from a series of testing carried out on dovetail joints, which is one of the most common traditional carpentry joints, during the 5th COST FP 1101 Training School, held in University of Minho, Portugal. Within this framework, a dovetail joint (with and without dowel) was tested under compression and tension. The experimentally obtained load-bearing capacity of the joints was then compared to the capacity values calculated using
\end{abstract}

K. Šobra $(\bowtie)$

Czech Technical University in Prague, Thákurova 7, 166 29, Prague 6, Czech Republic e-mail: karel.sobra@fsv.cvut.cz

C. Avez

University of Mons, Rue du Joncquois 53, 7000 Mons, Belgium

e-mail: coralie.avez@umons.ac.be

Y.D. Aktaş

University College London, Gower Street, WC1E 6BT London, UK

e-mail: y.aktas@ucl.ac.uk

R. de Rijk

Eindhoven University of Technology, 5612 AZ Eindhoven, Netherlands

e-mail: r.j.c.w.d.rijk@ student.tue.nl

I. Burawska

Warsaw University of Life Sciences, Nowoursynowska 166, 02-787 Warsaw, Poland

e-mail: izaburawska@o2.pl

J.M. Branco

ISISE, University of Minho, Campus de Azurém, 4800-058 Guimarães, Portugal

e-mail: jbranco@ civil.uminho.pt

(C) Springer International Publishing Switzerland 2016

H. Cruz et al. (eds.), Historical Earthquake-Resistant Timber Framing

in the Mediterranean Area, Lecture Notes in Civil Engineering,

DOI 10.1007/978-3-319-39492-3_18 
analytical models, and the failure modes were further discussed. The results showed that the experimentally obtained capacity values can be successfully reproduced by analytical models for dovetail joints without dowel. On the other hand, the capacity of a dovetail joint with dowel under compression or tension is always underestimated by analytical models.

Keywords Dovetail joints - Testing - Analytical models • Capacity

\section{Introduction}

Around the world, there is a variety of traditional/vernacular timber architecture that is widely considered as seismically resistant based on post-disaster field reconnaissance studies throughout centuries. Although there are cases where poor performance of timber buildings has been reported, mainly due to (1) aging, material degradation and bio-deterioration in timber, (2) lack of maintenance, (3) structural alterations that follow changes in the function of a building and (4) cumulative structural damage due to successive earthquakes as well as (5) disproportionately heavy roofs and (6) failure in the masonry sections of masonry-timber hybrid buildings which triggers an overall structural collapse, the performance of timber structure has mostly been found sufficient to bear seismic demand in areas where they are built. Thanks to the significant amount of static and dynamic experimental work in the last decades, both in the laboratory and on-site, this observation is no longer anecdotal [e.g. 1-3]. The testing efforts as well as in situ observations confirmed that timber structures' seismic performance is governed to a large extent by the joints. Joints are the weakest points within the structure, and they mostly fail when the timber members are still in the elastic range. Furthermore, they are the major energy dissipation mechanism within the structure; therefore they play a crucial role in overall robustness and the way that a structure handles the seismic demand.

Carpentry joints occupy an important place among most widely used connections in traditional timber buildings. Most studies regarding semi-rigid carpentry joints use testing and modelling tools to determine performance under axial or flexural loading and how the behaviour can be improved via different reinforcement techniques. Most studies regarding dovetail joints focus on rounded dovetail joints [e.g. 4-6]. A few remaining studies on lap dovetail connections include [7], where the authors carried out cyclic tests on log walls built by this type of joints to assess the in-plane response. In [8], authors test a frame with lap dovetail joints (inverted-trapezoid sectioned dovetail mortise-tenon joints, as authors name it) and discuss failure modes and obtained force-displacement relationships. The impact of geometrical features on mechanical behaviour was investigated using finite element models [e.g. 9] or experimentally [e.g. 10].

This paper summarizes the findings from testing of lap dovetail joints (with and without dowel) under compression and tension. It then discusses the observed 

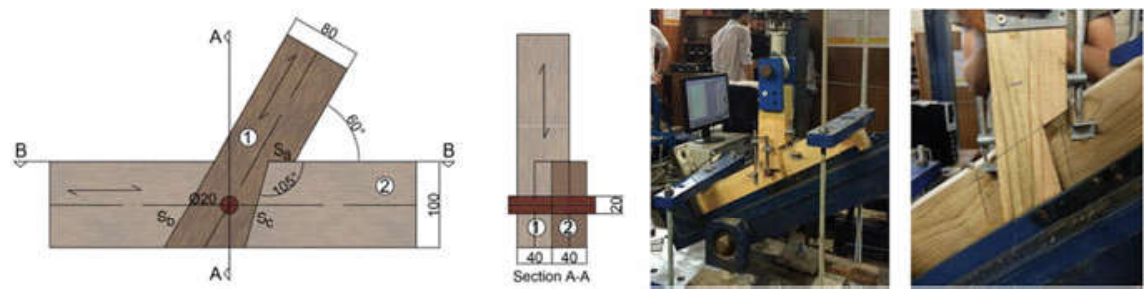

Fig. 1 Dovetail joints with and without dowel

Table 1 Test results (one sample per configuration)

\begin{tabular}{l|l|l}
\hline & Compression $(\mathrm{kN})$ & Tension $(\mathrm{kN})$ \\
\hline Dovetail without dowel & 17.51 & 4.74 \\
\hline Dovetail with dowel & 51.64 & 13.9 \\
\hline
\end{tabular}

failure mechanisms and compares the obtained capacity values to those calculated using models proposed in the relevant codes.

\section{Tests}

The tests described here were carried out on dovetail connections, which is among the most common traditional carpentry joints, during the 5th COST FP 1101 Training School that was held in University of Minho in Guimarães, Portugal, between the 11th and 14th of May 2015. The joints with and without dowel were tested under compression and tension (Fig. 1).

Dovetails used in this study for testing purposes were made of Scotch Pine (Pinus sylvestris) and Maritime Pine (Pinus pinaster) and the dowels were made of Massaranduba (Manilkara spp., tropical wood, assumed to be D60). The capacity values obtained at the end of tests under tension and compression are given in Table 1.

\section{Calculations}

Although there is no guideline in the Eurocode 5 [12] on how to design carpentry joints, calculations made here follow the Eurocode 5 (and Johansen's equations) philosophy: to every possible failure mode of the dovetail joint matches a failing load, and the minimum of all failing loads corresponds to the capacity of the connection. Material properties used in calculations for Scotch Pine and Maritime Pine were taken as mean values for Lodgepole Pine, which is the pine species with 
Table 2 Scotch pine or maritime properties [11]

\begin{tabular}{l|l|l|l}
\hline$\rho_{\text {mean }}\left(\mathrm{kg} / \mathrm{m}^{3}\right)$ & $\mathrm{f}_{\mathrm{v}, \mathrm{m}}(\mathrm{MPa})$ & $\mathrm{f}_{\mathrm{c}, 90, \mathrm{~m}}(\mathrm{MPa})$ & $\mathrm{f}_{\mathrm{t}, 90, \mathrm{~m}}(\mathrm{MPa})$ \\
\hline 410 & 6.1 & 4.2 & 2 \\
\hline
\end{tabular}

the lowest mean mechanical properties (Table 2) according to [11]. Maritime pine and Scotch pine properties are not fully available, therefore choosing the species of the same family exhibiting the lowest mean mechanical properties leads to conservative but still realistic results. Mean properties are preferred in calculations because design values and characteristic values are too conservative and probably do not reflect real properties of the wood samples tested here.

\section{Possible Failure Modes}

(a) Failure of the dowel (in tension and compression; Fig. 2)

The capacity of the dowel can be estimated using Johansen's equations (in single shear, timber-to-timber connection, EC5 equations given in Sect. 8.6), provided that the value of characteristic yield moment $\left(\mathrm{M}_{\mathrm{y}, \mathrm{r}, \mathrm{k}}\right)$ is adapted to timber dowel. This method was proposed and successfully used by authors of [13], who adapted Johansen's equations to account for design of all-wood connections (namely, plywood flitch plates and oak peg). Since a plastic hinge cannot develop with wood pegs, the adapted yield moment was defined as the moment for which rapid loss of load resistance was observed (since with wood dowels a ductile behaviour is not likely to occur). Since pegs were not tested in the present research, this adapted yield moment $\mathrm{M}_{\mathrm{y}, \mathrm{r}, \mathrm{k}}$ is evaluated through theory of material strength under plastic behaviour, but using a low value (i.e. $70 \mathrm{MPa}$ ) for "yield" strength (to take into account the rather brittle behaviour of bended wood dowels), as defined in (1).

(a)

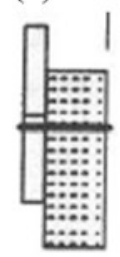

(b)

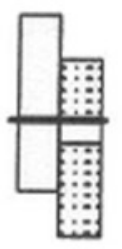

(c)

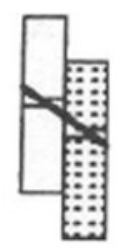

(d)

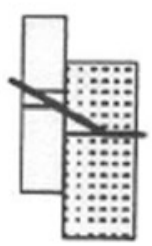

(e)

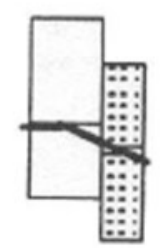

(f)

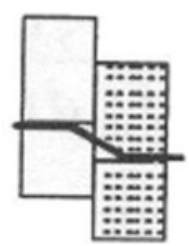

Fig. 2 Failure mode 1-fastener in single shear-according to Johansen [EC5, Sect. 8] 
Fig. 3 Failure mode 2splitting

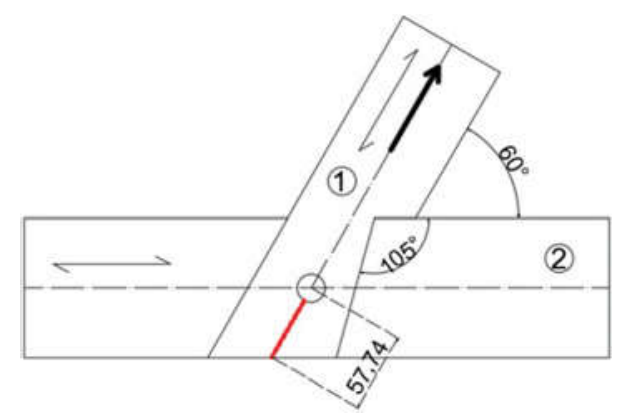

For cylindrical rods, the definition of the yielding moment is:

$$
M_{y, r, k}=f_{y, k} * \frac{D^{3}}{6}
$$

where $f_{y, k}$ is the yield strength, assumed to be $f_{m, k}$, i.e. $70 \mathrm{MPa}$. This estimation is conservative since we use the characteristic value for bending strength instead of the mean value; and $D$ is the diameter of the peg, i.e. $20 \mathrm{~mm}$.

For dovetails studied here, the failure mode identified using those equations (8.6 in EC5) is rotation of the dowel inside the timber block (i.e. failure mode (c) in EC5 8.6, see Fig. 2, with a calculated capacity equal to $8.53 \mathrm{kN}$ ), followed by "yielding" (i.e. dowel fracture) in one point of the timber dowel (i.e. failure mode (e), with a characteristic load-carrying capacity equal to $8.97 \mathrm{kN})$.

(b) Splitting near the dowel (in tension and compression; Fig. 3)

Splitting failure is prevented by following prescriptions regarding minimum edge/end distances from the dowel. Values given in the Eurocode 5 are for steel dowels (and are therefore too conservative for wood dowels, as highlighted and discussed in [13]), so in this paper rather minimum edge distances determined in [13] will be referred to: distance between the dowel and the end of the skew element must be greater or equal to 2.5 times the dowel diameter. This minimum end distance was respected in samples tested here, and by doing so splitting failure was prevented.

(c) Extraction of a shear plug around the dowel (in tension; Fig. 4)

Dovetail joints in tension may also fail by extraction of a plug around the dowel, failure due to excess of shear stresses in the skew element. The corresponding failure load can be estimated by multiplying the wood shear strength by the surface available to transfer shear.

(d) Excessive compression perpendicular to the grain on surface $\mathbf{S}_{\mathbf{a}}$ (in compression; Fig. 5)

In dovetail joints in compression, the load is transferred by compression along $\mathrm{S}_{\mathrm{a}}$ and compression and friction along $\mathrm{S}_{\mathrm{b}}$. This failure mode load is evaluated through 
Fig. 4 Failure mode 3shear plug

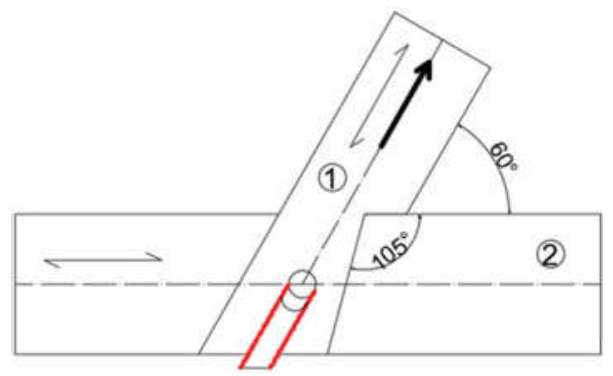

Fig. 5 Failure mode 4compression along $\mathrm{S}_{\mathrm{a}}$
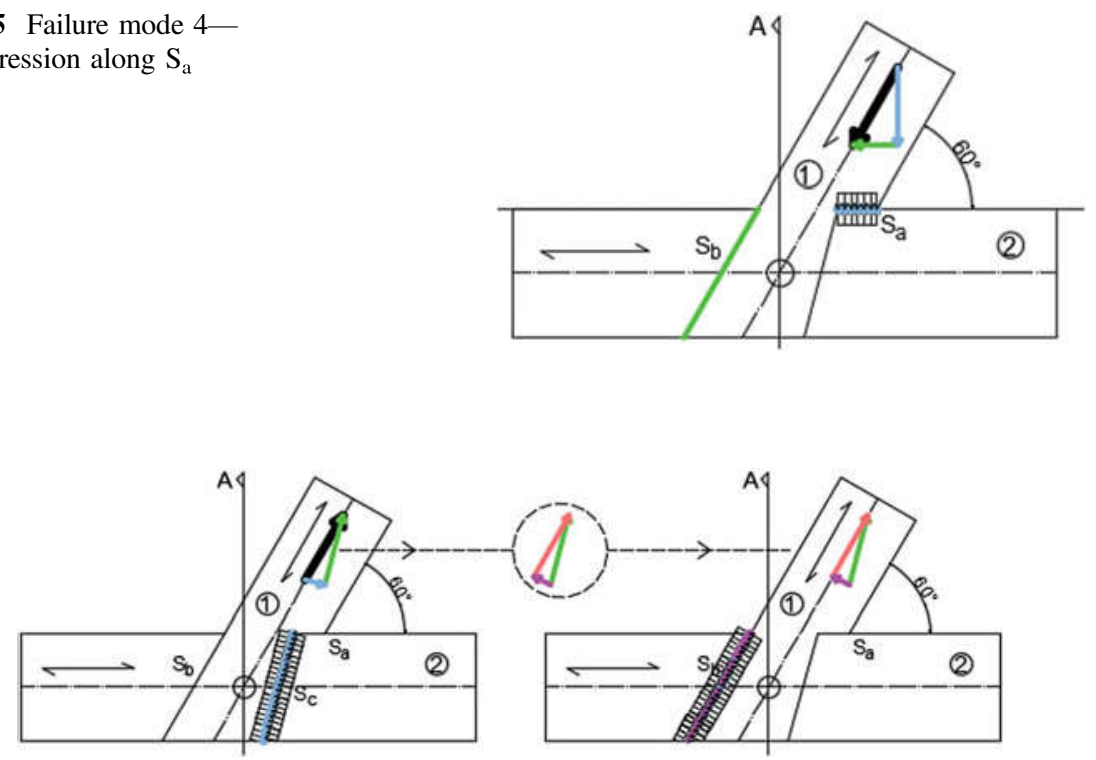

Fig. 6 Failure mode 5-compression on both sides of the dovetail

maximum permissible compression at an angle to the grain along $\mathrm{S}_{\mathrm{a}}$. It should though be noted that usually failure is due to incidental cracks (caused by tension perpendicular to the grain) and not to excessive compression.

(e) Excessive compression at an angle to the grain on both sides $S_{b}$ and $S_{c}$ of the dovetails (in tension; Fig. 6)

Tension of the dovetail leads to compression at an angle to the grain on surfaces $S_{b}$ and $S_{c}$. To evaluate the corresponding capacity, the tensile load is divided into forces inducing (i) compression perpendicular to the grain on $S_{c}$ and (ii) compression and friction along $\mathrm{S}_{\mathrm{b}}$. However, the load-bearing capacity is difficult to assess since this process of decomposition is iterative, and the wood crushing is rarely the 


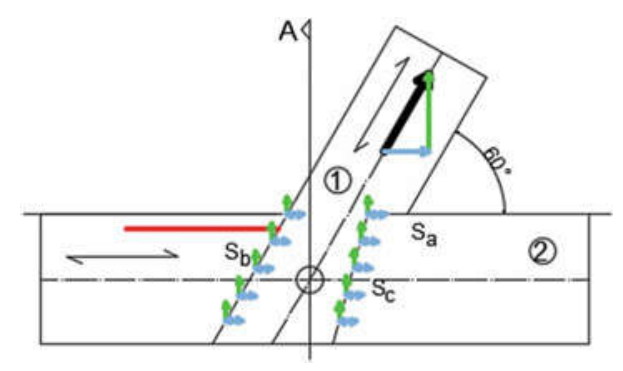

Fig. 7 Failure mode 6-interaction tension perpendicular and shear-method 1

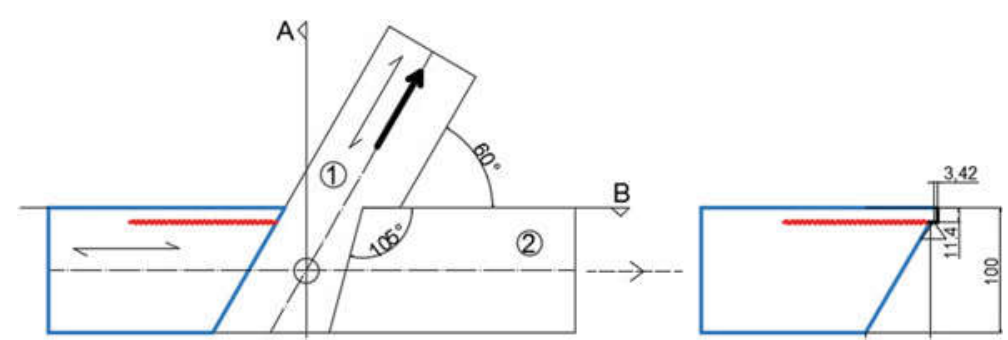

Fig. 8 Failure mode 6 -interaction tension perpendicular and shear-method 2

cause of a joint failure because of its ductility. Usually another failure mode (e.g. cracks due to shear parallel to the grain or tension perpendicular to the grain, see failure mode 6) occurs before wood completely crushes in compression (since the extra reserve of capacity is high).

\section{(f) Failure by tension perpendicular to the grain and shear}

(in tension; Figs. 7 and 8)

Interaction between tension perpendicular to the grain and shear parallel to the grain is highly dangerous for wood joints since it can induce cracks in the connection. The verification of the connection against this failure is made using two different calculations: (i) Calculations focusing on tensile stresses perpendicular to the grain and shear stresses separately (Fig. 7) and (ii) calculations inspired by Eurocode 5 guidelines for notched members, which take into account both tension perpendicular to the grain and shear in a single formula (EC5, Eq. 6.60). Here, we transpose this philosophy of design to the verification of the horizontal element, as illustrated on Fig. 8. The skew element is regarded as a support for the horizontal element.

Since the capacity calculated using method (ii) is lower (and therefore conservative), it will be regarded as the load inducing failure by tension perpendicular to the grain and shear (i.e. mode 6). The failure load is thus defined through expression (2): 


$$
\tau=\frac{1.5 * V}{b * h_{e f}} \leq k_{v} * f_{v, m}
$$

where $V$ is the shear load applying to the horizontal element (which is linked to the failure load), $h_{e f}$ is the position of the crack on failed sample, $f_{v, m}$ is the mean value for shear strength, and $\mathrm{k}_{\mathrm{v}}$ is a reduction factor defined in the Eurocode 5, Eq. (6.62). By calculating $V$, the failure load can then be obtained.

\section{Comparison with Experimental Results}

\section{In Compression}

For dovetails without dowel, the only possible failure mode is excessive compression on $\mathrm{S}_{\mathrm{a}}$, with a capacity of $17.75 \mathrm{kN}$ (Table 3). Experimental results agree with calculations since the failure was observed at $17.51 \mathrm{kN}$ due to compressionmore precisely to cracks of tension perpendicular to the grain induced by the compression deformation, see Fig. 9a.

For dovetails with dowel, the joint should first fail at the dowel. According to calculations, the first dowel failure mode should be the rotation of the dowel, followed by yielding of the dowel. Those dowel failures should occur at around 8.5 and $8.97 \mathrm{kN}$, respectively. The tested sample confirms failure modes since it shows both dowels "yielding" (Fig. 9c) and elongation of the holes in which the dowel is inserted (due either to dowel yielding or rotation), and deformation due to excessive compression on the horizontal element (Fig. 9b). We also see a crack due to tension perpendicular to the grain along the compressed surface $S_{a}$ on Fig. 9b. However, the load reached experimentally $(51.64 \mathrm{kN})$ is much higher than the calculated value $(8.53 \mathrm{kN})$ (Table 3 ).

Table 3 Possible failure modes and corresponding calculated capacities $(\mathrm{kN})$ for dovetails in compression

\begin{tabular}{l|l|l}
\hline Failure modes & With dowel & Without dowel \\
\hline Failure mode 1: dowel failure (by rotation) & $\mathbf{8 . 5 3}$ & - \\
\hline $\begin{array}{l}\text { Failure mode 4: excessive compression perpendicular } \\
\text { to the grain on surface } S_{\mathrm{a}}\end{array}$ & 17.75 & $\mathbf{1 7 . 7 5}$ \\
\hline
\end{tabular}

Bold values are considered as limit failure capacity. Those values are minimal calculated values for the joint 
(a)

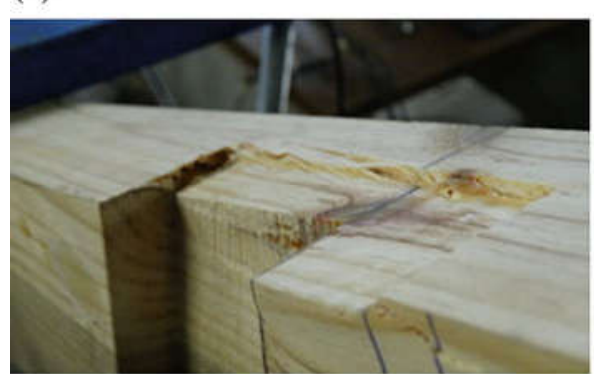

(c)

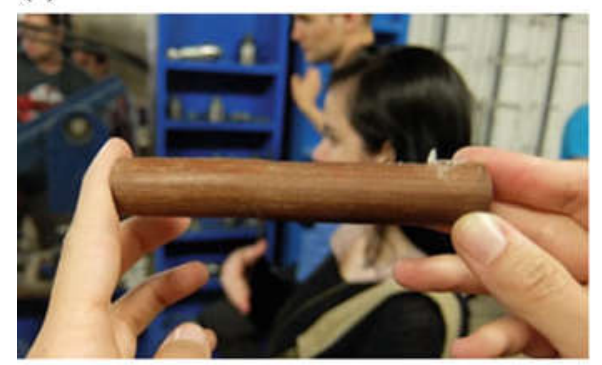

(b)

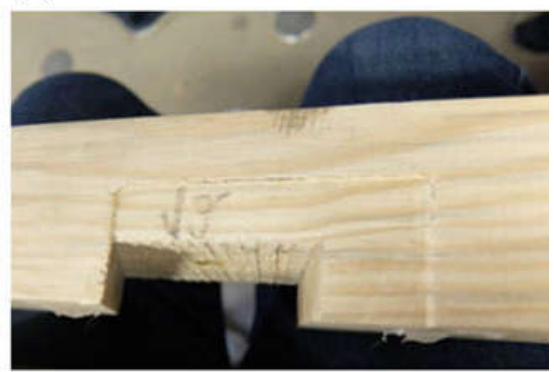

(d)

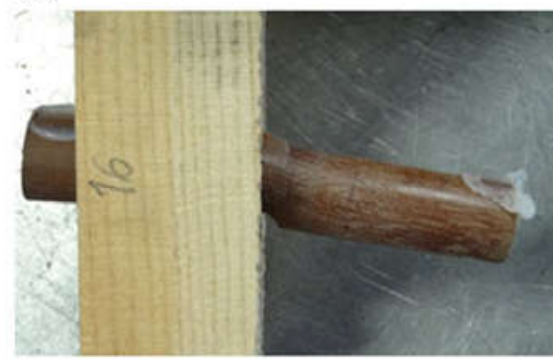

(e)

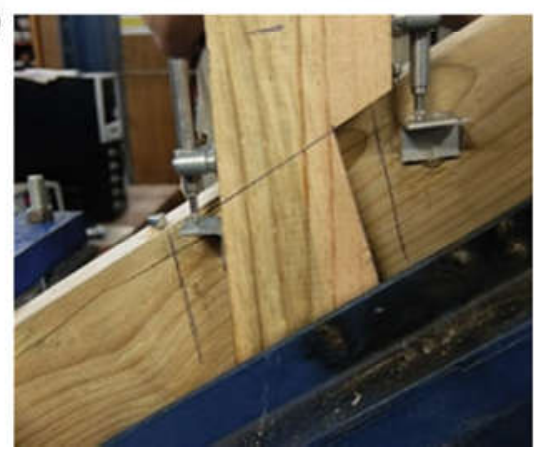

Fig. 9 Failures observed in the tested specimens. a Excessive compression on $S_{a}$ (+tensile cracks), b excessive compression on $S_{a}$, $\mathbf{c}$ dowel yielding, $\mathbf{d}$ failure of the dowel, $\mathbf{e}$ dovetail in tension: Tension + shear crack

\section{In Tension}

According to calculations, both dovetails with and without dowel should fail by cracking of the horizontal element due to combination of tension perpendicular to the grain and shear (Table 4). Regarding dovetails without dowel, experimental results are consistent with the analytically obtained values since the capacity is $4.74 \mathrm{kN}$ and the failed specimen exhibits a crack in the horizontal element (Fig. 9e).

However, for dovetails with dowel, the failure occurred by shear of the dowel at the interface between the two timber elements (see Fig. 9d), and the obtained 
Table 4 Possible failure modes and corresponding calculated capacities [kN] for dovetails in tension

\begin{tabular}{l|l|l}
\hline Failure modes & With dowel & $\begin{array}{l}\text { Without } \\
\text { dowel }\end{array}$ \\
\hline Failure mode 1: dowel failure (by rotation) & 8.53 & - \\
\hline Failure mode 3: extraction of a shear plug around the dowel & 28.18 & - \\
\hline $\begin{array}{l}\text { Failure mode 5: excessive compression at an angle } \\
\text { to the grain on both sides of the dovetails (i.e. on } \\
\text { surfaces } \mathrm{S}_{\mathrm{b}} \text { and } \mathrm{S}_{\mathrm{c}} \text { ) }\end{array}$ & 53.90 & 53.90 \\
\hline $\begin{array}{l}\text { Failure mode 6: failure by tension perpendicular } \\
\text { to the grain and shear }\end{array}$ & $\mathbf{3 . 2 1}$ & $\mathbf{3 . 2 1}$ \\
\hline
\end{tabular}

Bold values are considered as limit failure capacity. Those values are minimal calculated values for thejoint

capacity is $13.9 \mathrm{kN}$. This is because the load is transferred not only by compression on both sides of the dovetail (inducing tension perpendicular and shear responsible for cracking failure) but also through the dowel. Therefore, the dowel alleviates the part of the horizontal element that is subject to tensile and shear stresses and delays the failure (hence the load-bearing capacity is higher). It seems that the stiffness of the dowel is so high that it transferred most loads; hence, compression on sides of the dovetail did not induce enough tension perpendicular and shear on the horizontal element to crack it.

\section{Discussion}

As seen from the capacity values obtained at the end of tests, the dowel seems to triple the load-bearing capacity, both for compression and tension. Also, as seen in Fig. 10 below, the capacity of a dovetail joint without dowel can be quite accurately predicted, while the values obtained for a dovetail joint with dowel for different failure modes are rather scattered. It seems that the capacity of a dovetail joint with
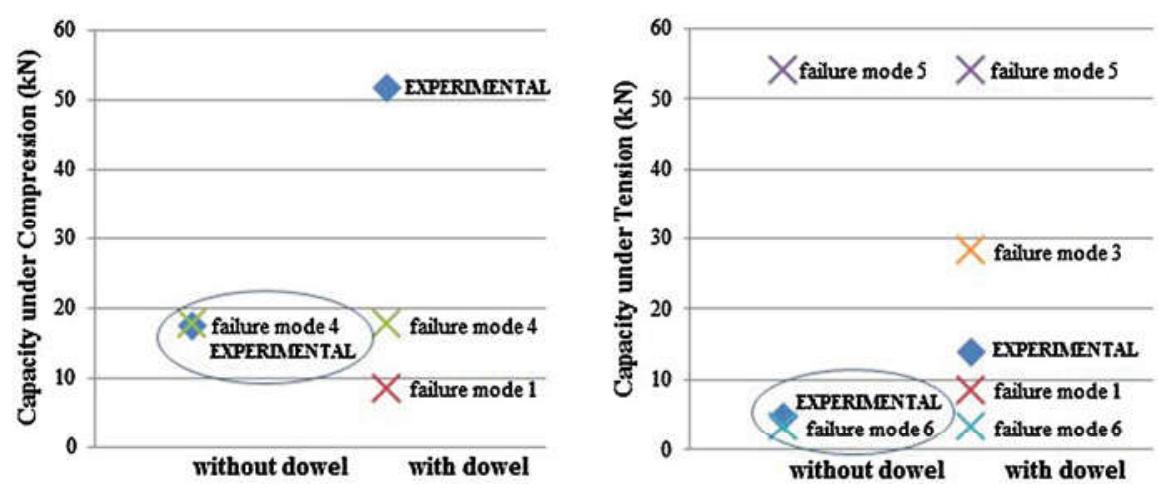

Fig. 10 Experimentally and analytically obtained capacity results 
Table 5 Comparison between experimental and analytical results

\begin{tabular}{l|l|l|l|l}
\hline \multirow{2}{*}{} & \multicolumn{2}{|l|}{ With dowel } & \multicolumn{2}{l}{ Without dowel } \\
\cline { 2 - 5 } & Tests $(\mathrm{kN})$ & Calculations $(\mathrm{kN})$ & Tests $(\mathrm{kN})$ & Calculations $(\mathrm{kN})$ \\
\hline In compression & 51.64 & 8.53 & 17.51 & 17.75 \\
\hline In tension & 13.9 & 3.21 & 4.74 & 3.21 \\
\hline
\end{tabular}

dowel under compression or tension (i.e. the minimum value among capacities calculated for each failure mode) is always underestimated by analytical models.

An important point to bear in mind while evaluating this result is that as dovetail joints with dowels are statically indeterminate structure, loads absorbed by each part of the joint depend on the relative stiffness of the constitutive parts of the joint. For instance, dovetail with dowel in compression transfers the load from the skew element to the horizontal element through the dowel and surface $S_{a}$ (spring analogy: parallel circuit, see Fig. 5). The fraction of the load transferred by the dowel depends on the stiffness of this dowel compared to the stiffness of the surface $S_{a}$. The relative stiffness, and therefore the fraction of the load absorbed by each part of the joint is difficult to assess analytically. Failure loads determined in this paper do not take into account this phenomenon, and thus underestimate the load-carrying capacity of dovetails with dowel.

\section{Conclusions}

Calculations based on the EC5 philosophy can predict accurately both capacity and failure mode of dovetails in tension or compression without a dowel, as recapped in Table 5.

However, behaviour of dovetails with dowel is more difficult to assess with a simple equation since the stiffness of the dowel and the surfaces under compression is of crucial importance to correctly identify the failure mode and estimate the corresponding ultimate load. Moreover, wood properties and yielding moment to be used at Johansen's equations need be estimated through approximated equations, which induce additional errors in the calculations. Hence, further investigations that take into account the relative stiffness of the dowel and the areas under compression are needed in order to make better estimates. Also, the dowel yielding moment should be determined experimentally.

The engineers who are commissioned for the condition assessment and retrofitting of traditional timber frame structures with carpentry joints should pay utmost attention to the discrepancy between the results obtained from testing and theoretical models. The carpentry joints are not standard, and this study clearly shows that the proposed models should be further fine-tuned to reflect their load bearing capacity and behaviour under certain actions. 
Acknowledgments The authors are grateful to COST Action for funding the FP1101 and RILEM 245 Training School at University of Minho in Guimarães, Portugal, thus, making this study possible.

\section{References}

1. Aktaş YD, Akyüz U, Türer A, Erdil B, Şahin Güçhan N (2014) Seismic resistance evaluation of traditional Ottoman timber-frame Hımış houses: frame loadings and material tests. Earthq Spectra 30:1711-1732

2. Poletti E, Vasconcelos G (2015) Seismic behaviour of traditional timber frame walls: experimental results on unreinforced walls. Bull Earthq Eng 13:885-916

3. Vieux-Champagne F, Sieffert Y, Grange S, Polastri A, Ceccotti A, Daudeville L (2014) Experimental analysis of seismic resistance of timber-framed structures with stones and earth infill. Eng Struct 69:102-115

4. Tannert T, Lam F, Vallée T (2011) Structural performance of rounded dovetail connections: experimental and numerical investigations. Eur J Wood Wood Prod 69:471-482

5. Tannert T, Haukaas T (2013) Probabilistic models for structural performance of rounded dovetail joints. J Struct Eng 139:1478-1488

6. Xu B-H, Bouchaïr A, Taazount M, Racher P (2013) Numerical 3D finite element modelling and experimental tests of rounded dovetail connection. Eur J Environ Civ Eng 17:564-578

7. Branco JM, Araujo JP (2012) Structural behaviour of log timber walls under lateral in-plane loads. Eng Struct 40:371-382

8. Li X, Zhao J, Ma G, Chen W (2015) Experimental study on the seismic performance of a double-span traditional timber frame. Eng Struct 98:141-150

9. Jeong GY, Park M-J, Hwang KH, Park J-S (2012) Effects of geometry on mechanical behaviour of dovetail connection. World Conference on Timber Engineering, Auckland

10. Kunecký J, Arciszewska-Kędzior A, Sebera V, Hasníková H (2015) Mechanical performance of dovetail joint related to the global stiffness of timber roof structures. Mater Struct. Available at http://link.springer.com/article/10.1617/s11527-015-0651-1

11. USDA (2010) Wood handbook: wood as an engineering material. United States Department of Agriculture-Forest Products Laboratory, Wisconsin

12. BSI (2004) Eurocode 5: BS EN1995-1:2004-Design of timber structures. CEN, Brussels

13. Chang WS, Thomson A, Harris R, Walker P, Shanks J (2011) Development of all-wood connections with plywood flitch plate and oak pegs. Adv Struct Eng 14(2):123-132 